3 Research S Suare

\title{
The Influence of Long and Short Cycle Schemes of Self-Cycling Fermentation on the Growth of $E$. Coli and S. Cerevisiae
}

\section{Yusheng Tan}

University of Alberta

Lisa Y. Stein

University of Alberta

Dominic Sauvageau ( $\boldsymbol{D}$ dominic.sauvageau@ualberta.ca )

University of Alberta https://orcid.org/0000-0002-1995-5523

\section{Research Article}

Keywords: Self-cycling fermentation, Escherichia coli, Saccharomyces cerevisiae, Short cycle scheme, Carbon dioxide evolution rate, Limiting nutrient, Cell replication

Posted Date: December 13th, 2021

DOI: https://doi.org/10.21203/rs.3.rs-1139754/v1

License: (a) (1) This work is licensed under a Creative Commons Attribution 4.0 International License. Read Full License 


\section{Abstract}

Self-cycling fermentation (SCF), a cyclic process in which cells divide once per cycle, has been shown to lead to improvements in productivity during bioconversion and, often, whole-culture synchronization. Previous studies have found that in some cases, the completion of synchronized cell replication occurred simultaneously with depletion of a limiting nutrient. However, exceptions were also observed when the end of cell doubling occurred before the exhaustion of the limiting nutrient. In order to better understand the underlying mechanisms and impacts of these growth patterns on bioprocessing, we investigated the growth of Escherichia coli and Saccharomyces cerevisiae in long- and short-cycle SCF strategies. Three characteristic events linked to SCF cycles were identified: (1) the completion of synchronized cell replication, (2) the depletion or a plateau of the limiting nutrient, and (3) characteristic points of control parameters (e.g., the minimum of dissolved oxygen and the maximum of carbon dioxide evolution rate). Three major trends stemming from this study and SCF literature were observed: (A) co-occurrence of the three key events in SCF cycles, (B) cycles for which cell replication ended prior to the co-occurrence of the other two events, and (C) cycles for which the time of depletion or a plateau of the limiting nutrient occurred later than the concurrence of the other two events. Based on these observations, a novel definition for SCF is proposed.

\section{Introduction}

Self-cycling fermentation (SCF) is an advanced fermentation technique that improves productivity in many bioconversion processes (Sauvageau and Cooper 2010; Storms et al. 2012; Agustin 2015; Wang et al. 2017). It is a semi-continuous, unsteady-state, cyclical mode of operation, in which, following an initial batch growth, cycles are triggered when the depletion of a limiting nutrient occurs (Brown and Cooper 1991; Sauvageau et al. 2010). Many metabolism- and growth-related parameters, including dissolved oxygen (DO), carbon dioxide evolution rate (CER), oxidation-reduction potential (ORP), and exit gas mass flow rate, have served as control parameters to fulfill the automated feedback-control necessary for SCF cycling (Brown 2001; Wang et al. 2020, 2021). When a pre-established condition of the control parameter is met, SCF cycling is triggered and exactly one half of the working volume is harvested before being replenished with the same amount of fresh medium (Brown and Cooper 1991; Sauvageau et al. 2010).

The increased productivity demonstrated in many SCF studies (Brown and Cooper 1991; Zenaitis and Cooper 1994; Wentworth and Cooper 1996; Sauvageau and Cooper 2010; Storms et al. 2012; Wang et al. $2017,2020)$ is strongly related to the operational characteristics of this semi-continuous process.

Compared to a conventional batch reactor (BR), SCF cycles have negligible lag or stationary phases. Also, in contrast to chemostats, SCF greatly minimizes nutrient waste, especially the limiting one, and the products can be harvested at higher concentrations, facilitating downstream processing. Moreover, since the limiting nutrient is completely depleted every cycle, SCF operation has shown strong potential for pollutant degradation when pollutants were used as limiting carbon or nitrogen sources (Brown and Cooper 1992; Sarkis and Cooper 1994; Hughes and Cooper 1996; Brown et al. 1999, 2000). 
SCF and continuous phasing (Dawson 1965, 1972; Sheppard and Cooper 1990, 1991), its forebearer, share many similarities. One is the entrainment mechanism that describes the periodic availability of essential nutrients inducing synchronization (Sheppard and Dawson 1999). A sharp increase in cell count within a narrow time window during a given cycle was observed for both continuous phasing and SCF (Sheppard and Dawson 1999). Flow cytometry validated that synchrony had been achieved during continuous phasing of bacteria by the determination of DNA content and cell sizes (Fritsch et al. 2005). Transcriptomic patterns were used to confirm that synchrony was obtained during SCF of yeast (Tan et al. 2022). Many relevant trends could be observed in the prior study, including that most genes related to DNA replication and half of the genes associated with the yeast cell cycle were significantly up-regulated at the same point during the early SCF cycles (Tan et al. 2022).

The incorporation of a feedback control system in SCF is a major difference and improvement compared to continuous phasing. It prevents either starvation or washout, and triggers medium replacement precisely at the exhaustion of the limiting nutrient (Brown 2001). The decisive influence of cell growth on cycle time is paramount to SCF operation. In a large number of studies implementing the SCF technique, the cycle time was found to be equal to the doubling time of the same microorganism growing under the same nutrient conditions (Sheppard and Cooper 1990; Brown and Cooper 1991; Sarkis and Cooper 1994; McCaffrey and Cooper 1995; Wentworth and Cooper 1996; Brown et al. 1999). Subsequently, SCF cycle time was used to reflect the nutrient quality of the environment in a number of physiological studies; wherein a shorter cycle time suggested more efficient cell replication and thus a more beneficial nutrient condition (Brown 2001).

Although many SCF studies have depicted the concurrence of the completion of the cell cycle with the depletion of the limiting nutrient and a minimum in DO (corresponding to a maximum in CER) (Sheppard and Cooper 1990; Brown and Cooper 1991; Sarkis and Cooper 1994; McCaffrey and Cooper 1995; Wentworth and Cooper 1996; Brown et al. 1999), recent studies conducted with Escherichia coli and Saccharomyces cerevisiae (Sauvageau et al. 2010; Storms et al. 2012; Agustin 2015; Tan et al. 2022) showed the completion of synchronized cell division (corresponding to the maximum in CER) occurring before depletion of the limiting nutrient. The end of synchronized cell doubling was identified by a sudden step-wise increase in cell density (Sauvageau et al. 2010; Storms et al. 2012; Agustin 2015) and flattened expression of selected cyclin genes (Tan et al. 2022). Revisiting earlier SCF results, a similar misalignment between the end of synchronized cell division and the exhaustion of the limiting nutrient was also found for other microorganisms (Sheppard 1993; Marchessault and Sheppard 1997; Crosman et al. 2002). However, the trends in the control parameters could be different (Sheppard 1993; Marchessault and Sheppard 1997). With these discrepancies in mind, we show that an SCF short cycle strategy, cycling when the maximum in CER occurred, could lead to stable cyclic operation of E. coli and $S$. cerevisiae with enhanced volumetric biomass productivity. Also, transcriptional shifts of selected cyclin genes were explored during $S$. cerevisiae short cycles. These results confirmed the time at which cell replication of these microbes was completed and led to the identification of three typical trends during all SCF scenarios. In trend A, the end of synchronized cell replication, the exhaustion of the limiting nutrient, and the characteristic points of control parameters (three characteristic events) occur concomitantly. In 
Trend B, cell doubling completes before the co-occurrence of the other two events. Finally, in Trend C, the limiting nutrient is depleted or reaches a plateau after the joint occurrence of the other two events. The results from this study enable a better understanding of the cellular processes during SCF and can guide the development of more efficient bioconversion processes.

\section{Results}

\section{E. coli grown in BR and SCF operation}

E. coli MG1655 was grown in a batch set-up for over $24 \mathrm{~h}$. Two CER local minima were observed, one at 2 $\mathrm{h}$ and another at $7.5 \mathrm{~h}$ (Fig. $1 \mathrm{~A})$. These were likely due to either metabolic stalling or transitions between metabolic regimes. $\mathrm{OD}_{600}$ reached its maximum at $7.5 \mathrm{~h}$, as $\mathrm{CER}$ reached a local minimum, and remained at approximately 2.5 for the remainder of the experiment (Fig. 1B). Glucose was consumed rapidly until $\sim 9 \mathrm{~h}$, corresponding to the second CER maximum, after which point it remained relatively constant. Glucose, which was expected to be the limiting nutrient, was not exhausted even after an extension of the experiment well into stationary phase. Therefore, the abundance of nitrogen, in the form of ammonium, nitrate and nitrite, was examined; nitrogen compounds were found to remain abundant during the entire batch operation (Fig. 1C). Additional calcium and iron, and yeast extract were added to fresh media in independent experiments; these approaches did not result in glucose exhaustion after batch operation (data not shown). Hence, the cessation of glucose consumption was likely not due to a deprivation of a limiting nutrient but more likely due to an inhibitory effect of excessive intermediate metabolites. For example, organic acid overproduction could impact growth. However, $\mathrm{pH}$ only decreased from 6.76 to below 6 during operation, which is unlikely to cause cessation of growth by itself.

E. coli MG1655 was then grown under SCF operation. The first 26 cycles were run in an SCF long cycle scheme, while the succeeding 10 cycles were operated under a short cycle scheme. The transition from long to short cycles occurred within cycle 27 , which could be regarded as a disrupted long cycle and was not considered a cycle in either mode of operation. In the long cycle scheme, cycles were triggered when the decreasing trend in CER flattened, while in the short cycle operation, cycling was triggered when CER reached its maximum. For SCF long cycles, a repeatable pattern of CER was established directly after the second cycle - an increase in the early stages of a cycle, a decrease during the late campaign, and a plunge upon cycling (Fig. 2A). The cycle time during long cycle operation averaged $4.54 \pm 0.32 \mathrm{~h}$ for cycles 3 to 26 (Fig. 2A). When the operation was tuned to the short cycle scheme, readaptation occurred within the first two cycles after the transition cycle, and a new stable pattern of CER was obtained after it (Fig. 2C). The new CER pattern only displayed a decrease in CER upon cycling, and the cycle time was reduced to $1.43 \pm 0.06 \mathrm{~h}$ for short cycles 3 to 10 (Fig. 2C). Meanwhile, the CER maximum increased from $0.0026 \mathrm{~mol} / \mathrm{L} / \mathrm{h}$ to $0.0036 \mathrm{~mol} / \mathrm{L} / \mathrm{h}$ and the average CER (integrated CER per cycle time) significantly increased once long cycles were switched to short cycles. Moreover, the stability of SCF long cycle and short cycle operation demonstrated that cells completed one round of cell replication per cycle, regardless of the cycling regime. 
The increase in $\mathrm{OD}_{600}$ and the decrease in glucose concentration were essentially linear towards the end of the cycling regimes represented by long cycle 24 and short cycle 10 (Fig. 2B and 2D). Long cycle 24 accumulated more biomass, consistent with a greater amount of glucose consumed, over its significantly greater cycle time, as compared to short cycle 10 (Fig. 2B and 2D). The yield of E. coli biomass from glucose was $0.34 \mathrm{~L} \cdot \mathrm{g}$ glucose $\mathrm{e}^{-1}$ during long cycle 24 and was $0.63 \mathrm{~L} \cdot \mathrm{g}$ glucose $\mathrm{e}^{-1}$ for short cycle 10 . The productivity of $E$. coli biomass was $0.15 \mathrm{~h}^{-1}$ and $0.42 \mathrm{~h}^{-1}$ for the long and short cycles, respectively. The glucose consumption rate was also improved in short cycle 10 (Fig. 2B and 2D). By adjusting to a short cycle scheme, the yield of $E$. coli cells from glucose increased 1.8-fold, and volumetric biomass productivity was improved 2.7 -fold (both relative to the long cycle scheme).

\section{S. cerevisiae grown in SCF operation}

Similarly to E. coli, S. cerevisiae was cultivated under SCF long cycle and short cycle schemes; the long cycle operation cycled when the decreasing CER flattened, whereas the short cycle scheme triggered cycling upon reaching a maximum in CER (Fig. 3A and 3D). Both modes of operation were found to be highly stable and reproducible directly after their first cycles considering their CER profiles (Fig. 3A and 3D), suggesting that $S$. cerevisiae cells completed one generation of cell proliferation within a long or short cycle time. However, similarly to $E$. coli experiments, there was a significant difference regarding the shapes of CER curves - no CER decrease was observed during short cycles. CER maxima increased from $0.009 \mathrm{~mol} / \mathrm{L} / \mathrm{h}$ to $0.011 \mathrm{~mol} / \mathrm{L} / \mathrm{h}$ between long and short cycle operation; the average CER (integrated CER per cycle time) also significantly increased (Fig. 3A and 3D). Cycle times were significantly different, with an average cycle time of $12.11 \pm 0.73 \mathrm{~h}$ for long cycles 2 to 16 and $3.80 \pm 0.27 \mathrm{~h}$ for short cycles 2 to 20 (Fig. 3A and 3D).

Fig. 3B and $3 \mathrm{C}$ depict biomass accumulation and glucose consumption in cycles 1 and 10, respectively, of long cycle operation. The CER maximum in SCF long cycle 1 (Fig. 3A) corresponded to a transition point between exponential phase and diauxic shift during BR growth (Fig. 3B). Glucose, the limiting nutrient, was depleted at the end of the cycles, consistent with the co-occurrence of the flattening point of CER (cycling condition) and the exhaustion of the limiting nutrient. In contrast, during the short cycle scheme, although similar patterns in $\mathrm{OD}_{600}$ and glucose concentration were observed in cycles 1 and 20 (Fig. 3E and 3F, respectively), glucose was not exhausted by the end of the cycles. Consequently, the $\mathrm{OD}_{600}$ at the end of each cycle was lower and increases in $\mathrm{OD}_{600}$ were affected accordingly compared to the long cycle counterparts (Fig. $3 \mathrm{E}$ and $3 \mathrm{~F}$ ). Nonetheless, volumetric productivity of $S$. cerevisiae cells was $0.17 \mathrm{~h}^{-1}$ during long cycle 10 and $0.28 \mathrm{~h}^{-1}$ during short cycle 20, a 1.6-fold increase (Fig. 3C and 3F; Table 1). The glucose consumption rate was also found to be greater in short cycle 20 (Fig. 3C and 3F). However, biomass yield was comparable between the long and short cycles -0.22 and $0.21 \mathrm{~L} \cdot \mathrm{g}$ glucose

${ }^{1}$, respectively (Fig. $3 \mathrm{C}$ and 3F; Table 1). Additionally, the nitrogen source, ammonium, was always in excess and was not the limiting nutrient (data not shown).

\section{Relative expression levels of selected cyclin genes in S. cerevisiae}


Relative expression levels (fold changes) of $C L N 1, C L N 2, C L B 3, C L B 1$, and $C L B 2$, were determined for $S$. cerevisiae growing in SCF short cycles 1 and 21 using APCR (Fig. 4A and 4B, respectively). Generally, fold changes of the cyclin genes during BR (short cycle 1) late-log phase were not significant: slight decreases in expression were found for $C L B 1$ and $C L B 2$, and slight increases in expression were observed for CLN1 and CLN2 over the cycle (Fig. 4A). In contrast, during short cycle 21 (with a cycle time of $3.7 \mathrm{~h}$ ), the following observations were made: (1) CLB1 and CLB2 (paralog genes) were significantly up-regulated during the early stages of the short cycle up to a cycle time of $2.8 \mathrm{~h}$, with peaks in expression at approximately $1.4 \mathrm{~h}$; (2) the expression of $C L N 1$ and $C L N 2$ (paralog genes) was generally stable but showed significant up-regulation at $2.8 \mathrm{~h}$; and (3) in comparison, CLB3 transcription remained relatively steady throughout the short cycle (Fig. 4B). Identical trends in relative expression levels of the cyclin genes were observed in replicated short cycle experiments (Fig. S1A and S1B for SCF short cycles 1 and 21 , respectively).

Considering the significant sequential up-regulation of these cyclin genes, it can be established that some extent of synchrony was achieved during the short cycle operation, even though this could not be directly corroborated using cell counts due to flocculation of the yeast cells (data not shown). During a standard yeast cell cycle, $C L N 1$ and $C L N 2$ are up-regulated prior to $C L B 1$ and $C L B 2 ; C L N 1$ and $C L N 2$ are expressed in $\mathrm{G} 1$ and S phases while $C L B 1$ and $C L B 2$ during M phase (Fitch et al. 1992; Futcher 1996; Cho et al. 1998; Feldmann 2012). However, here in the short cycle 21, the up-regulation of CLB1 and CLB2 was shown to be earlier than that of CLN1 and CLN2. This indicated that partially synchronized (if not completely synchronized) cell replication started and ended in the middle of the short cycles, rather than being aligned with the SCF cycle progression.

\section{Discussion}

\section{E. coli BR Operation}

During E. coli BR operation, two major CER peaks could be observed (Fig. 1A), which is consistent with a prior E. coli study (Sauvageau et al. 2010). During the current study, nitrogen, calcium, iron, and yeast extract were not shown to limit the growth. Little glucose was consumed during the late stages of BR and it was not depleted by the end of BR (Fig. 1B). The restricted growth was most likely due to the accumulation of organic acids (e.g., acetic acid), resulting from bacterial Crabtree effect (Mustea and Muresian 1967), rather than the depletion of a limiting nutrient. Excessive organic acids might be produced from rapid growth in the early stages of BR, partly inhibiting the subsequent stages of growth and preventing the full consumption of glucose. Some future investigations can be carried out to identify the mechanisms of this inhibition and eliminate barriers towards complete consumption of glucose.

\section{SCF Long Cycle and Short Cycle Operation}

Much like the case for $E$. coli BR operation, E. coli SCF long cycles did not exhaust glucose when CER flattened (cycling condition) (Fig. 2B). This was not the case for S. cerevisiae undergoing SCF operation, wherein glucose depletion was observed at the end of BR and long cycles (Fig. 3B and 3C). As discussed 
earlier, the accumulation of organic acids might have an inhibitory effect on E. coligrowth. Previous work investigating E. coli undergoing SCF long cycles (Sauvageau et al. 2010) found that glucose was totally consumed by the time CER stopped decreasing; however, while that study was performed with similar nutrient conditions, it used a different strain of E. coli (ATCC 11303) (Sauvageau et al. 2010).

The improvement in production of $E$. coli biomass was significant once SCF operation was adjusted to a short cycle scheme; 1.8-fold and 2.7-fold increases in yield and volumetric productivity, respectively (Table 1). In the previous study investigating SCF long cycles with E. coli ATCC 11303 (Sauvageau et al. 2010 ) the yield was found to be $0.23 \mathrm{~L} \cdot \mathrm{g}$ glucose ${ }^{-1}$, and the productivity of E. coli cells was $0.28 \mathrm{~h}^{-1}$ (also shown in Table 1; calculated based on an original figure (Sauvageau et al. 2010) using Eq. 1 and 2). In comparison, the yield and volumetric productivity during the current short cycle operation also prevailed. As for S. cerevisiae cells grown in SCF operation, short cycles led to a 1.6-fold increase in volumetric productivity while providing a similar yield to long cycles (Table 1). It was also noted that the average glucose consumption rate and average CER were enhanced during short cycles of both $E$. coli and $S$. cerevisiae, despite lower cell density (Fig. 2 and 3 ) - meaning more glucose was consumed per cell and more $\mathrm{CO}_{2}$ was released per cell. That is to say, cellular activity was generally more intense during SCF short cycles.

Table 1 Yield and volumetric productivity in cellular biomass production during SCF long and short cycle operation

\begin{tabular}{|lll|}
\hline SCF Operation & $\begin{array}{l}\text { Yield of Cells }(\mathrm{L} \cdot \mathrm{g} \\
\left.\text { glucos }{ }^{-1}\right)\end{array}$ & $\begin{array}{l}\text { Volumetric Productivity of } \\
\text { Cells }\left(\mathrm{h}^{-1}\right)\end{array}$ \\
\hline E. coli long cycle operation (this study) & 0.34 & 0.15 \\
\hline $\begin{array}{l}\text { E. coli long cycle operation (2010) } \\
\text { (Sauvageau et al. 2010) }\end{array}$ & $0.23^{\mathrm{a}}$ & $0.28^{\mathrm{a}}$ \\
\hline E. coli short cycle operation (this study) & 0.63 & 0.42 \\
\hline S. cerevisiae long cycle operation (this study) & 0.22 & 0.17 \\
\hline $\begin{array}{l}\text { S. cerevisiae short cycle operation (this } \\
\text { study) }\end{array}$ & 0.21 & 0.28 \\
\hline
\end{tabular}

a values were calculated using data from (Sauvageau et al. 2010) and Eq. 1 and 2.

Significant improvements in yield, productivity, and metabolic activity highlight the advantages of the SCF short cycle scheme as compared to the long cycle counterpart. Yield and productivity would likely be further improved if the SCF short cycle strategy were used in the context of recent $E$. coli and $S$. cerevisiae SCF studies, such as E. coli biomass production (Sauvageau et al. 2010), bacteriophage production (Sauvageau and Cooper 2010; Storms et al. 2014), recombinant protein production (Storms et al. 2012), ethanol fermentation (Wang et al. 2017, 2020), and shikimic acid production (Agustin 2015). Instantaneous specific productivity of bacteriophage, recombinant protein, and shikimic acid was found 
to be optimal near the completion of synchronized cell replication (corresponding to a maximum in CER) during SCF long cycle operation (Storms et al. 2012, 2014; Agustin 2015).

In specific, the results observed in this study for S. cerevisiae SCF long cycle operation generally agree with a preceding study (Tan et al. 2022). Growing the engineered yeast strain in SCF long cycles had substantially improved shikimic acid yield and productivity compared to BR (Tan et al. 2022). Hence, it may be possible to further enhance shikimic acid production by implementing the SCF short cycle strategy. Based on the improved productivity of cellular biomass (Table 1), the production rate of the primary metabolite will highly likely be further reinforced in SCF short cycles.

The incomplete depletion of glucose during short cycles might be the only concern for the implementation of this SCF scheme. To address this, recycling of the carbon source might be considered in future studies.

A close link between CER maximum and the completion of synchronized cell division can be established. Firstly, the cycle time of short cycles - from start-of-cycle to CER maximum - allowed one generation of complete cell doubling. Considering the SCF cycling process is based on the replacement of exactly onehalf of the working volume of the fermenter, if E. coli and S. cerevisiae cells had not completed one round of cell replication within each cycle, washout would have occurred and the CER profile would have been unrepeatable. The short cycles, however, were stable and repeatable. Secondly, during previous SCF studies based on long cycles with E. coli (ATCC 11303 (Sauvageau et al. 2010) and CY15050 (Storms et al. 2012)) and the engineered S. cerevisiae (CEN.PK 113-1A Mata (Agustin 2015)), step-wise doublings in cell count were observed at the CER maxima. This suggested that cell replication was in unison, and synchronized cell doubling was completed when CER reached its maximum. Thirdly, significant upregulation of DNA replication-related genes and selected cyclin genes (CLN1,CLN2,CLB3,CLB1, and CLB2) were observed only during the first-half of $S$. cerevisiae SCF long cycles (Tan et al. 2022). It is very likely that there was little replication activity after the maximum in CER. Fourthly, the cycle time of SCF long cycles was significantly longer than the expected doubling time in the same nutrient conditions. In contrast, the duration of short cycles was very close to those doubling times.

As to $S$. cerevisiae SCF short cycles, the expression profiles of the investigated cyclin genes provided valuable information (Fig. 4). Firstly, the amplitudes and sequential changes in up-regulation suggested that a certain level of cell synchrony was established. Cyclical changes in glucose concentration established by the mode of operation provided a forcing function to induce the entrainment effect required for cell synchrony; greater glucose availability early in the SCF cycles preferentially favored some stages of the cell cycle. It was also noted that, compared to SCF long cycles, a decrease in up-regulation amplitudes was observed during short cycles (Fig. 4B and Tan et al. 2022). This was likely due to the incomplete utilization of glucose, resulting in a tamer entrainment effect during short cycles. Secondly, the sequence of cyclin genes expression suggested that the replication of partially synchronized cells started from the middle of the short cycles and was completed at the same point in the subsequent cycle. CLN1 and CLN2 were expressed later than CLB1 and CLB2 during SCF short cycles (Fig. 4B) - an inverse 
sequence compared to the standard yeast cell cycle (Fitch et al. 1992; Cho et al. 1998). This unexpected, distinct, cycle-spanning cell replication pattern in short cycles was likely caused by other driving forces apart from the oscillation of glucose concentration, as the nutrient cycle itself is expected to lead to an alignment between the starts of SCF and cell cycles.

This leads to another question - might synchronized yeast cell replication also present a cycle-spanning pattern during SCF long cycles, starting from the middle of a long cycle and ending at the same point in the succeeding long cycle? The answer should be no. One reason is that there was no significant expression of selected cyclin genes during the second-half of long cycles (Tan et al. 2022). Hence, there was hardly any replication activity during the late stages of long cycles. Moreover, the onsets of SCF long cycles and the yeast cell cycle were aligned, as suggested by the congruent expression sequence of the cyclin genes during the first half of long cycles and the standard yeast cell cycle. Furthermore, the cycle time of long cycles was more than twice the doubling time of $S$. cerevisiae in the same nutrient conditions. It is unlikely that one round of cell replication occurred throughout the whole cycle time of long cycles.

Identical trends and amplitudes of cyclin gene expression during BR late-log phase were identified not only between replicate experiments in the present study (Fig. 4A and S2A) but also amongst current qPCR results, previous qPCR results, and previous RNA-Seq results (Tan et al. 2022). This great alignment of the gene expression profiles across different studies and analytical techniques significantly increases confidence in the trends observed. Consequently, relative quantification results were considered to truly reflect transcriptional changes during SCF short cycles (Fig. 4B).

\section{An Overview of Characteristic Events in SCF}

Significant differences in the occurrence of some SCF key events can be observed among SCF studies with different microorganisms implemented. These characteristic events include: (1) the time at which the limiting nutrient was depleted or reached a plateau, (2) the characteristic values of control parameters, and (3) the completion of one generation of synchronized cell division.

Nitrogen or carbon sources are frequently set as the limiting nutrients dictating the cycling of SCF operation. Control parameters used to establish cycling conditions have included dissolved oxygen (DO), carbon dioxide evolution rate (CER), or oxidation-reduction potential (ORP) (Brown 2001). Mass flow rate of the exit gas has also been used for SCF of $S$. cerevisiae Superstart ${ }^{\mathrm{TM}}$ producing ethanol (Wang et al. 2020) and was a direct reflection of CER under anaerobic conditions. In studies of phenol degradation using Pseudomonas putida ATCC 12633 (Hughes and Cooper 1996) and Acinetobacter calcoaceticus RAG-1 ATCC 31012 grown on hexadecane (van Walsum and Cooper 1993), CER patterns were found to mirror DO patterns, and CER maximum aligned with DO minimum. Under aerobic conditions, this relationship between CER and DO would generally be true (cautions on rare exceptions). In another study investigating toluene removal using P. putida ATCC 12633 undergoing SCF (Brown et al. 2000), the inflection point of ORP was observed near the concurrence of CER maximum and DO minimum. However, 
ORP patterns during SCF operation are generally more complex than other parameters. An increasing trend in ORP was observed in the toluene removal study using P. putida ATCC 12633 (Brown et al. 2000), while a decreasing trend was shown in the removal of oxidized nitrogen using Pseudomonas denitrificans ATCC 13867 (Brown et al. 1999). The presence and absence of oxygen in these two studies were likely responsible for these diverging patterns. In contrast, DO and CER generally present similar patterns amongst various studies and hence have been more often applied as the control parameter. Overall, it is illustrated that DO minimum would coincide with CER maximum during SCF operation, and the inflection point of ORP is likely close to this point. In the present study, the time at which this event occurs is referred to as the control parameters' "characteristic values" or "characteristic points".

In many SCF studies published before 2010, co-occurrence was always identified for the depletion of a limiting nutrient and the characteristic values of control parameters. SCF cycling was triggered upon this concurrence unless an extended cycle strategy was applied. In antibiotic production using Streptomyces aureofaciens ATCC 12416c (Zenaitis and Cooper 1994), phenol degradation using P. putida ATCC 12633 (Hughes and Cooper 1996), and cultivating Bacillus subtilis ATCC 21332 (Sheppard and Cooper 1991), DO minimum occurred concomitantly with nitrogen depletion or the complete removal of phenol. Moreover, the co-occurrence of the completion of cell replication with the aforementioned two key events was observed in a wealth of SCF studies, and this is summarized as Trend A in Fig. 5A. The first SCF upgrade from continuous phasing identified that the depletion of nitrogen, DO minimum, and the doubling endpoint of optical density (OD) took place at the same moment (Sheppard and Cooper 1990). In sophorolipid production using Candida bombicola ATCC 22214 (McCaffrey and Cooper 1995) and citric acid production using Candida lipolytica ATCC 20390 (Wentworth and Cooper 1996), cell count doubled within a narrow time window near the minimum in DO, concomitant with the exhaustion of the nitrogen source. In A. calcoaceticus RAG-1 ATCC 31012 grown on ethanol (Brown and Cooper 1991) and the degradation of aromatic compounds using P. putida ATCC 12633 (Sarkis and Cooper 1994), the completion of cell doubling co-occurred with carbon source exhaustion and DO minimum. Similarly, in oxidized nitrogen removal using P. denitrificans ATCC 13867 (Brown et al. 1999), the end of doubling of cell dry weight corresponded to the inflection point of ORP and nitrogen depletion.

The reliability of Trend A (Fig. 5A) had been considered universal. For example, in studies tackling hydrocarbon degradation using A. calcoaceticus RAG-1 ATCC 31012 (Brown and Cooper 1992) and cultivating B. subtilis ATCC 21332 (Sheppard and Cooper 1991), the authors directly took the equivalence of SCF cycle time and cell doubling time as a default. However, this was only true when synchronized cell division was accomplished upon initiating SCF cycling. Also, it should be noted that the end point of the doubling of OD or dry weight does not necessarily represent the doubling endpoint of cell number. These can be decoupled and display different trends in synchronized populations - the cell count increases in a step-wise manner, while OD or dry weight present a continuous, near-linear increase regardless of the completion of synchronized cell division (Marchessault and Sheppard 1997; Storms et al. 2012).

Moreover, during polyhydroxybutyrate (PHB) production using Alcaligenes eutrophus DSM 545 (Marchessault and Sheppard 1997) and the growth of B. subtilis ATCC 10774 (Sheppard 1993), while the 
minimum in DO and the nitrogen source depletion coincided, synchronized cell replication was completed much earlier - in the middle of the SCF cycles. As the timing of the cell cycle end point showed a significant difference, these studies serve as representations for Trend B in Fig. 5B. In summary, for most of the microbial systems used in earlier SCF studies, the depletion of a limiting nutrient and characteristic values of control parameters (DO minimum, CER maximum, or ORP inflection point) occurred concurrently at the end of each SCF cycle (Trends A and B in Fig. 5A and 5B). One round of synchronous cell doubling was completed at the same time (Trend A in Fig. 5A) or, in some instances, in the middle of the cycles (Trend B in Fig. 5B).

Compared to Trends A and B, the scenario observed in a study investigating biosurfactant production using Corynebacterium alkanolyticum ATCC 21511 growing on hexadecane in SCF (Crosman et al. 2002) was substantially different. DO minimum and the completion of synchronized cell division occurred concomitantly, but a considerable amount of carbon source was left over. Recent SCF works using E. coli ATCC 11303 (Sauvageau et al. 2010), E. coli CY15050 (Storms et al. 2012), and engineered S. cerevisiae CEN.PK 113-1A Mata (Agustin 2015) depicted an identical trend - cell count doubled step-wise at the maximum in CER (at the cycle midpoint), but glucose, the limiting nutrient, was only exhausted once the decrease in CER flattened (at the end of the cycles). In ethanol fermentation using $S$. cerevisiae Superstart ${ }^{\mathrm{TM}}$ undergoing SCF (Wang et al. 2020), glucose was depleted upon the time when CER flattened (reflected by exit gas mass flow rate in anerobic conditions), though cell counts were not reported due to clumping of the yeast cells. As mentioned earlier, the same trend was observed in the present study when cultivating E. coli MG1655 or engineered S. cerevisiae CEN.PK 113-1A Mata (except that, for E. coli undergoing SCF long cycles, the end of cycle was due to an inhibitory effect rather than glucose depletion). Trend $\mathrm{C}$ in Fig. $\mathrm{CC}$ is used to describe the pattern observed in these studies.

Moreover, transcriptional evidence during $S$. cerevisiae SCF short cycles presented in this study revealed a likely cell replication pattern in short cycles - partially synchronized cell cycle starting and ending in the middle of short cycles. This cycle-spanning mode of cell replication is presented by the black dashed line in Fig. 5C. Overall, in studies displaying Trend C, the flattening of CER decrease or DO increase coincided with the depletion or a plateau of the limiting nutrient at the end of SCF long cycles, but synchronized cell replication was completed in the middle of the long cycles, corresponding to CER maximum or DO minimum. SCF short cycles ended at CER maximum or DO minimum, but partially synchronized cell replication likely started and ended in the middle of the short cycles. The limiting nutrients were not depleted by the end of the SCF short cycles.

The discrepancies amongst the three major trends in the characteristic events during SCF operation were likely derived from intrinsic differences in the microorganisms and nutrient environments used. $A$. eutrophus and B. subtilis ATCC 10774 following Trend B, and C. alkanolyticum, E. coli, and S. cerevisiae following Trend $C$ likely sensed nutrient conditions more actively and adopted a feed-forward strategy (Levy and Barkai 2009) - in which cells proactively sensed external changes and regulated gene transcription and expression prior to the alteration of the growth rate (Levy and Barkai 2009). Completing one generation of the synchronized cell cycle but deciding not to continue the proliferation at the expense 
of the remaining limiting nutrient seemed to be the growth strategy of these microorganisms (Fig. 5B and 5C). On the contrary, for a number of microorganisms following Trend $A$, all the available limiting nutrient was used in completing the cell doubling (Fig. 5A). The difference between $A$. eutrophus and $B$. subtilis ATCC 10774 in Trend B, and C. alkanolyticum, E. coli, and S. cerevisiae in Trend C is expected to lie in the respiratory intensity between the end of the cell cycle and the time at which the limiting nutrient was depleted or reached a plateau. For the former group, the intensity of respiration increased even after synchronized cell replication. Therefore, the characteristic value of the control parameter (DO minimum) co-occurred with the exhaustion of the limiting nutrient but not with the end of cell doubling (Fig. 5B). For microbes displaying Trend $\mathrm{C}$, respiration slowed significantly after synchronized cell replication (during the consumption of residual limiting nutrient), and therefore CER maximum or DO minimum occurred at the completion of synchronized cell doubling but not at the depletion or a plateau of the limiting nutrient (Fig. 5C).

Different nutrient conditions can lead to different physiologies and affect the trends in SCF. For example, implementing different types of limiting nutrients - nitrogen or carbon - in a continuous phased culture tremendously affected where synchronized cell replication of Candida utilis $(\mathrm{Y}-900)$ ended when the cycle time was set to 4, 6, 8, and $12 \mathrm{~h}$ (Müller and Dawson 1968). Further studies on this topic could lead to more in-depth understanding of the physiological patterns during SCF.

Limiting nutrient depletion has been one of the original premises of SCF, but a broader picture is emerging. The Trend $\mathrm{C}$ observed in some studies suggests a deviation from the original description of SCF - SCF does not necessarily require limiting nutrient depletion. Consequently, a novel description of SCF is proposed below, taking into consideration all SCF scenarios presented in Fig. 5. This new SCF definition excludes the requirements of limiting nutrient depletion and joint occurrence of the key events.

SCF is a semi-continuous fermentation approach that allows the completion of one generation of microbial cell replication during each cycle. The cycling procedure comprises harvesting precisely one half of the working volume and then replenishing with the equivalent amount of fresh medium. Cycling is dictated by microbial growth and metabolism and is triggered automatedly based on monitoring one or more growth- and/or metabolism-associated sensing elements (e.g., DO, CER, ORP, exit gas mass flow rate, etc.). SCF cycling takes place directly after the completion of one generation of cell proliferation or with a delay, depending on the microorganism, the initial nutrient conditions, and the control parameter conditions for cycling being implemented. SCF cycling is not necessarily related to the time at which the limiting nutrient is depleted or reaches a plateau. If limiting nutrient depletion or a plateau does not cooccur with the cell cycle completion, we identify SCF operation that cycles in advance of exhaustion or a plateau of the limiting nutrient as "short cycle", and correspondingly, SCF operation that cycles upon depletion or a plateau of the limiting nutrient as "long cycle" (Fig. 5). "Extended cycle" is generally referred to as SCF operation that cycles beyond exhaustion or a plateau of the limiting nutrient (Fig. 5).

\section{Conclusions}


Previous SCF operation of E. coli and S. cerevisiae triggered cycling upon glucose depletion when the CER flattened. In the present study, SCF short cycle operation of E. coli and S. cerevisiae were cycled at the maximum in CER and led to stable and reproducible short cycles. Notably, compared to SCF long cycles, volumetric biomass productivity was significantly improved during SCF short cycles. Further transcriptional analysis for selected $S$. cerevisiae cyclin genes inferred a cycle-spanning mode of cell replication during SCF short cycles. Viable SCF short cycles also helped identify the maximum in CER as the endpoint of cell replication during long cycles. Moreover, a thorough overview of previous SCF studies summarized the occurrence of three SCF characteristic events, (1) the completion of synchronized cell replication, (2) the depletion or a plateau of the limiting nutrient, and (3) the characteristic points of control parameters, into three typical trends. A novel description of SCF was then proposed to include all scenarios of SCF operation and clear definitions for SCF "short cycle", "long cycle", and "extended cycle".

This work highlights a diversity in SCF operation and shows the potential of SCF as a research tool to explore microbial physiological properties - including nutrient use, proliferation strategies, and respiration intensity. It also demonstrates that short cycle schemes, in particular, can be used to improve performance of bioconversion. With trends in the key events summarized and the establishment of a clear definition of SCF, the present work consolidates and deepens our understanding of the SCF technique and its influences on microbial populations. Finally, it provides a solid framework to guide the further design and implementation of SCF-based processes.

\section{Methods/experimental}

\section{Strains, Media, and Pre-cultures}

Escherichia coli MG1655 (CGSC 6300) was used in E. coli studies. Luria-Bertani (LB) broth (all chemicals used in this study were purchased from Fisher Scientific and Sigma Aldrich, Canada) was used for agar plates $(1.5 \% \mathrm{w} / \mathrm{v}$ of agar). Semi-defined liquid medium was used in Erlenmeyer flasks or fermenters, containing $6 \mathrm{~g} / \mathrm{L}$ sodium phosphate dibasic, $4 \mathrm{~g} / \mathrm{L}$ ammonium nitrate, $4 \mathrm{~g} / \mathrm{L}$ potassium phosphate monobasic, $0.014 \mathrm{~g} / \mathrm{L}$ disodium EDTA, $0.05 \mathrm{~g} / \mathrm{L}$ yeast extract, $0.01 \mathrm{~g} / \mathrm{L}$ calcium chloride dihydrate, 0.01 $\mathrm{g} / \mathrm{L}$ iron sulfate heptahydrate, $6 \mathrm{~g} / \mathrm{L}$ glucose, and $0.2 \mathrm{~g} / \mathrm{L}$ magnesium sulfate heptahydrate. Pre-cultures were grown in $250-\mathrm{mL}$ Erlenmeyer flasks at $37^{\circ} \mathrm{C}, 250 \mathrm{rpm}$ for $12 \mathrm{~h}$. Approximately $4 \times 10^{10}$ cells $(10 \mathrm{~mL})$ were withdrawn from pre-cultures and used to inoculate the $1-\mathrm{L}$ fermenter working volume to achieve $1 \%$ $\mathrm{v} / \mathrm{v}$ inoculation.

An engineered Saccharomyces cerevisiae (Mookerjee 2016), genetically modified to overproduce shikimic acid based on parental strain CEN.PK 113-1A MATa, was kindly provided by Prof. Vincent Martin at Concordia University. E. coli $A R O B, A R O D$, and the feedback-resistant variant of constitutive ARO4 (ARO4 K229L) were introduced using a pYES plasmid with URA3 for auxotrophic selection (Mookerjee 2016). $1.92 \mathrm{~g} / \mathrm{L}$ yeast synthetic drop-out medium excluding uracil was used for auxotrophic selection on agar plates (1.5\% w/v of agar). $6.7 \mathrm{~g} / \mathrm{L}$ yeast nitrogen base (YNB) without amino acids and $20 \mathrm{~g} / \mathrm{L}$ dextrose comprised liquid medium. Pre-cultures were grown in Erlenmeyer flasks at $30{ }^{\circ} \mathrm{C}$ and $150 \mathrm{rpm}$ for $48 \mathrm{~h}$. 
Approximately $8 \times 10^{8}$ cells $(10 \mathrm{~mL})$ from pre-cultures were added to the $1-\mathrm{L}$ working volume in the fermenter to achieve $1 \% \mathrm{v} / \mathrm{v}$ inoculation.

\section{SCF Configuration and Operation}

The SCF configuration was previously described in (Sauvageau et al. 2010; Tan et al. 2022), with a 2-L stainless steel fermenter (10.5 cm I.D.). The feed system included a 10-L carboy (Nalgene, Fisher Scientific) containing fresh medium, a peristaltic pump (77201-60, Cole Parmer), a solenoid valve (SV125, Omega), and a glass isolator. The harvesting system consisted of a solenoid valve (SV125, Omega) and a 10-L harvest carboy (Nalgene, Fisher Scientific). Air was supplied by passing through an air regulator (R07-200-RGKA, Norgren), a sterilized water bottle (for stabilization and humidification), a rotameter (03294-20, Cole Parmer), and a HEPA filter (Whatman). Exit gas flew through a glass condenser and a HEPA filter (Whatman). Carbon dioxide $\left(\mathrm{CO}_{2}\right)$ in the exit gas was measured with an in-line $\mathrm{CO}_{2}$ gas sensor $\left(\mathrm{CO}_{2}\right.$-BTA, Vernier) located after the filter. Precise volume control during cycling was realized using highlevel and low-level optical sensors (ELS-900 series, Gems Sensors) at $1 \mathrm{~L}$ and $0.5 \mathrm{~L}$, respectively. The temperature was monitored and controlled using a K-type thermocouple (GKQSS-18G-10, Omega) and a cartridge heater (CIR-1032/120V, Omega). Real-time data of cycle time, temperature, carbon dioxide evolution rate (CER, based on $\mathrm{CO}_{2}$ concentration in the exit gas), and the first derivatives of CER over 20 min and $60 \mathrm{~min}$ (referred to as short dCER and long dCER) were monitored and recorded by LabView (National Instruments) via an OPTO 22 data acquisition board. A LabView program was used to control conditions and automate cycling.

The fermenter temperature was maintained at $37^{\circ} \mathrm{C}$ during bacterial growth and $30^{\circ} \mathrm{C}$ during yeast growth. Agitation at $250 \mathrm{rpm}$ with a Rushton impeller (4-cm diameter) and aeration at $400 \mathrm{~mL} / \mathrm{min}$ for $E$. coli and $845 \mathrm{~mL} / \mathrm{min}$ for $S$. cerevisiae provided sufficient mixing and aerobic conditions. During the SCF cycling procedure, agitation was ceased to maintain liquid level stability. Cell culture drainage driven by gravity stopped when the liquid level reached the low-level sensor. Fresh medium was then pumped into the bioreactor until the 1-L working volume was reached.

The following conditions were used to trigger automated cycling. For the $E$. coli SCF long cycle operation: (1) cycle time was greater than $90 \mathrm{~min}$; (2) the absolute value of short dCER was less than $0.02 \mathrm{ppm} / \mathrm{min}$; (3) long dCER was less than 0. For the E. coli SCF short cycle scheme: (1) cycle time was greater than 60 min; (2) short dCER was less than $-0.02 \mathrm{ppm} / \mathrm{min}$. For the $S$. cerevisiae SCF long cycle scheme: (1) cycle time was greater than $300 \mathrm{~min}$; (2) CER was less than $3000 \mathrm{ppm}$; (3) the absolute value of short dCER was less than $0.05 \mathrm{ppm} / \mathrm{min}$; (4) long dCER was less than 0 . For the $S$. cerevisiae SCF short cycle strategy: (1) cycle time was greater than $110 \mathrm{~min}$; (2) short dCER was less than $-0.02 \mathrm{ppm} / \mathrm{min}$; (3) CER was more than $3000 \mathrm{ppm}$.

\section{Batch Reactor Configuration and Operation}

Figure S2 depicts the BR set-up, which was adapted from the SCF set-up and used when BR operation was decoupled from SCF operation in cultivating E. coli. Cultivation conditions during BR were congruent 
with those used for SCF operation. Additionally, the first cycles of SCF operation are analogues of BR.

\section{Measurement of Optical Density, Glucose, Ammonium, and Nitrate \& Nitrite}

A spectrophotometer (Ultrospec 50, Biochrom) was used to measure optical density of culture samples at a wavelength of $600 \mathrm{~nm}\left(O D_{600}\right)$.

Glucose concentration was determined using the reducing sugar method (Miller 1959). Dinitrosalicylic acid (DNS) reagent was used, containing $10 \mathrm{~g}$ dinitrosalicyclic acid, $2 \mathrm{~g}$ phenol, $0.5 \mathrm{~g}$ sodium sulfite, and $10 \mathrm{~g}$ sodium hydroxide in $1 \mathrm{~L}$ deionized water. $20 \mu \mathrm{L}$ of the filtered samples were mixed with $140 \mu \mathrm{L}$ of DNS reagent, followed by a 5-min incubation at $95^{\circ} \mathrm{C}$. Samples were then cooled on ice for 5 min to stop the reactions. After that, $840 \mu \mathrm{L}$ of deionized water was added. Samples were finally measured through a spectrophotometer (Ultrospec 50, Biochrom) set to a wavelength of $540 \mathrm{~nm}$. A standard curve was established based on standards and used for quantification.

Nitrogen measurement followed methods detailed in (Bollmann et al. 2011). To measure ammonium, a solution of $12 \mathrm{~g} / \mathrm{L}$ of sodium hydroxide was mixed with another containing $85 \mathrm{~g} / \mathrm{L}$ sodium salicylate and $0.6 \mathrm{~g} / \mathrm{L}$ sodium nitroprusside at a $2: 1$ volume ratio. $375 \mu \mathrm{L}$ of this freshly prepared mixture was added to $750 \mu \mathrm{L}$ of every sample. $150 \mu \mathrm{L}$ of $0.2 \mathrm{~g} / \mathrm{L}$ sodium dichloroisocyanurate was then added, followed by 30 min of incubation in a dark environment. After incubation, absorbance of samples was measured at 660 nm using a spectrophotometer (Ultrospec 50, Biochrom). A standard curve was established based on standards. The concentration of ammonium in samples was determined based on the standard curve. To measure nitrate and nitrite, $75 \mu \mathrm{L}$ of a catalyst solution containing $35.4 \mathrm{mg} / \mathrm{L}$ copper sulfate pentahydrate and $0.9 \mathrm{~g} / \mathrm{L}$ zinc sulfate monohydrate was added to $500 \mu \mathrm{L}$ of every sample. Then, $75 \mu \mathrm{L}$ of $40 \mathrm{~g} / \mathrm{L}$ sodium hydroxide and $75 \mu \mathrm{L}$ of $1.71 \mathrm{~g} / \mathrm{L}$ hydrazine sulfate were added sequentially, and samples were incubated in the dark for $15 \mathrm{~min}$. After incubation, $250 \mu \mathrm{L}$ of $10 \mathrm{~g} / \mathrm{L}$ sulfanilamide dissolved in $3.5 \mathrm{M}$ hydrochloric acid and $75 \mu \mathrm{L}$ of $1 \mathrm{~g} / \mathrm{L}$ naphthylethylene diamine dichloride were added sequentially, and samples were incubated in the dark for an additional $10 \mathrm{~min}$. Samples were finally assessed by measuring absorbance at $540 \mathrm{~nm}$ using a spectrophotometer (Ultrospec 50, Biochrom). A standard curve was established based on standard solutions and used for quantification.

\section{Calculation of Yield and Productivity for Biomass Production}

Eq. 1 and 2 were used to calculate the yield and productivity in the production of E. coli or S. cerevisiae cells. 


$$
\begin{array}{ll}
Y_{X / S}=\frac{\Delta O D_{600}}{-\Delta c_{S}} & \text { - Eq. } 1 \\
r_{P}=\frac{\Delta O D_{600}}{\Delta t} & \text { - Eq. } 2
\end{array}
$$

$Y_{X / S}$ is the yield of $E$. coli and $S$. cerevisiae biomass (assessed by $\mathrm{OD}_{600}$ ) on glucose in $\mathrm{L} \cdot \mathrm{g}$ glucose ${ }^{-1}$. $r_{P}$ represents the volumetric productivity of $E$. coli and $S$. cerevisiae biomass (assessed by $\mathrm{OD}_{600}$ ) in $\mathrm{h}^{-1}$. $c_{S}$ is the substrate concentration in g glucose $\mathrm{L}^{-1}$. $t$ represents operation time in $\mathrm{h}$.

\section{qPCR Experiments for S. cerevisiae}

Samples $(0.5 \mathrm{~mL})$ were collected at multiple sampling points during S. cerevisiae BR and SCF operation. Cells were centrifuged (13,000 g, $2 \mathrm{~min})$, and the supernatant was discarded. Total RNA purification was performed using a Masterpure Complete DNA and RNA Purification Kit (Lucigen). The main steps consisted of cell lysis, protein precipitation, nucleic acid recovery, and genomic DNA removal. The manufacturer's instructions were followed with the following modifications: dithiothreitol (DTT) was added to $1 \mathrm{mM}$ before cell lysis, and disodium EDTA ( $\mathrm{pH}=8.5$ ) was added to $2.5 \mathrm{mM}$ at the end of the DNA removal step to cease the digestion by DNase I. After RNA extraction, a NanoDrop 1000 (Thermo Fisher) and a Bioanalyzer 2100 (Agilent) were used to measure the concentration, quality, and integrity of the total RNA samples. A High-Capacity cDNA Reverse Transcription Kit with RNase Inhibitor (Thermo Fisher) was used for reverse transcription, implementing random primers and a standard temperature program. qPCR experiments were carried out using PowerUp SYBR Green Master Mix (Thermo Fisher) in a QuantStudio 3 real-time PCR instrument (Thermo Fisher). Each condition was tested in triplicate. A BR sample collected at the transition point from late-log phase to diauxic shift (at $16.2 \mathrm{~h}$ ) was utilized as the reference sample for all alignments. ACT1 and $A L G 9$ were used as reference genes based on literature (Teste et al. 2009; Cankorur-Cetinkaya et al. 2012; Davison et al. 2016). The following genes were selected to assess the yeast cell cycle (Fitch et al. 1992; Futcher 1996; Cho et al. 1998; Feldmann 2012): CLN1 and CLN2 (up-regulated from G1 phase to early S phase), CLB3 (expressed in late S phase and G2 phase), CLB1 and CLB2 (accumulating transcripts in mitotic phase). Primers were designed using Primer3 (Untergasser et al. 2012). Their sequences, amplicon sizes, and efficiencies determined via standard curve experiments are shown in Table 2. Relative gene expression levels were calculated using the double delta $C_{t}$ method (Livak and Schmittgen 2001). 
Table 2

Primer sequences, amplicon sizes, and efficiencies for qPCR experiments

\begin{tabular}{|c|c|c|c|}
\hline Gene & Forward and reverse primers & Amplicon size (bp) & Efficiency (\%) \\
\hline \multirow[t]{2}{*}{ ACT1 } & 5囚-CTCGTGCTGTCTTCCCATCT-3囚 & \multirow[t]{2}{*}{69} & \multirow[t]{2}{*}{101.15} \\
\hline & 5囚-TTTGACCCATACCGACCAT-3】 & & \\
\hline \multirow[t]{2}{*}{ ALG9 } & 5囚-ACATCGTCGCCCCAATAAA-3】 & \multirow[t]{2}{*}{132} & \multirow[t]{2}{*}{92.69} \\
\hline & 5囚-CGTAAAATGCTCTACCCAAAATCTT-3囚 & & \\
\hline \multirow[t]{2}{*}{ CLN1 } & 5囚-CTCGTATTCCACGCCTTTCT-3囚 & \multirow[t]{2}{*}{114} & \multirow[t]{2}{*}{93.52} \\
\hline & 5囚-CGTCCCAGTTCAGAGTATCCA-3囚 & & \\
\hline \multirow[t]{2}{*}{ CLB3 } & 5囚-AGGATGAAGAAGAAGACCAGGA-3】 & \multirow[t]{2}{*}{69} & \multirow[t]{2}{*}{105.86} \\
\hline & 5囚-GCTCCCAGACCAATGTATCA-3】 & & \\
\hline \multirow[t]{2}{*}{ CLB1 } & 5囚-CTCAGCGGCAATGTTCCT-3】 & \multirow[t]{2}{*}{90} & \multirow[t]{2}{*}{102.68} \\
\hline & 5囚-GCCTTTGTGTAACCACCACT-3囚 & & \\
\hline \multirow[t]{2}{*}{ CLN2 } & 5囚-TTCCTCATCTCAAAGCCACA-3囚 & \multirow[t]{2}{*}{130} & \multirow[t]{2}{*}{93.93} \\
\hline & 5囚-TGACTGCTGCTGACCAAATT-3】 & & \\
\hline \multirow[t]{2}{*}{ CLB2 } & 5囚-TGCCTTTTCATTGCCTCTAA-3囚 & \multirow[t]{2}{*}{77} & \multirow[t]{2}{*}{89.35} \\
\hline & 5囚-GCACCGTCTGTCTCTGATG-3】 & & \\
\hline
\end{tabular}

\section{List Of Abbreviations}

SCF: Self-cycling fermentation; DO: Dissolved oxygen; CER: Carbon dioxide evolution rate; ORP:

Oxidation-reduction potential; BR: Batch reactor; DNA: Deoxyribonucleic acid; OD: Optical density; qPCR: Quantitative polymerase chain reaction; RNA: Ribonucleic acid; PHB: Polyhydroxybutyrate; LB: LuriaBertani; YNB: Yeast nitrogen base; DNS: Dinitrosalicylic acid; DTT: Dithiothreitol; EDTA: Ethylenediaminetetraacetic acid.

\section{Declarations}

Ethics approval and consent to participate

Not applicable.

\section{Consent for publication}

Not applicable. 
Availability of data and materials

The data generated or analyzed during this study are included in this published article and its supplementary information file.

\section{Competing interests}

The authors declare that they have no competing interests.

\section{Funding}

This work was supported by the Natural Sciences and Engineering Research Council of Canada (NSERC) Discovery Grant program, the Canada First Research Excellence Fund - Future Energy Systems, the Canada Foundation for Innovation - John R. Evans Leaders Fund, the Government of Alberta - Ministry of Economic Development and Trade Small Equipment Grant, and the University of Alberta Faculty of Engineering.

\section{Authors' contributions}

YT and DS conceptualized the work. YT designed the experiments and performed data acquisition, analysis, interpretation, and visualization. DS participated in the design of experiments. DS and LS contributed to data analysis and interpretation. YT wrote and edited the manuscript. DS and LS edited the manuscript. DS supervised the project. DS and LS acquired funding. All authors read and approved the final manuscript.

\section{Acknowledgements}

We would like to thank Prof. Vincent Martin from Concordia University for providing the engineered $S$. cerevisiae strain, Troy Locke at MBSU from the University of Alberta for the help in operating the Bioanalyzer, and Melissa Harrison for the help in editing the manuscript.

\section{Authors' information}

${ }^{1}$ Department of Chemical and Materials Engineering, University of Alberta, Edmonton, Alberta, Canada.

${ }^{2}$ Department of Biological Sciences, University of Alberta, Edmonton, Alberta, Canada.

\section{References}

1. Agustin RVC (2015) The Impact of Self-Cycling Fermentation on the Production of Shikimic Acid in Populations of Engineered Saccharomyces cerevisiae. University of Alberta

2. Bollmann A, French E, Laanbroek HJ (2011) Isolation, cultivation, and characterization of ammoniaoxidizing bacteria and archaea adapted to low ammonium concentrations. In: Methods in Enzymology. Academic Press Inc., pp 55-88 
3. Brown WA (2001) The self-cycling fermentor - development, applications, and future opportunities. In: Recent Research and Developments in Biotechnology and Bioengineering. pp 4: 61-90

4. Brown WA, Cooper DG (1991) Self-cycling fermentation applied to Acinetobacter calcoaceticus RAG1. Appl Environ Microbiol 57:2901-2906. https://doi.org/10.1128/aem.57.10.2901-2906.1991

5. Brown WA, Cooper DG (1992) Hydrocarbon degradation by Acinetobacter calcoaceticus RAG-1 using the self-cycling fermentation technique. Biotechnol Bioeng 40:797-805. https://doi.org/10.1002/bit.260400707

6. Brown WA, Cooper DG, Liss SN (1999) Adapting the self-cycling fermentor to anoxic conditions. Environ Sci Technol 33:1458-1463. https://doi.org/10.1021/es980856s

7. Brown WA, Cooper DG, Liss SN (2000) Toluene removal in an automated cyclical bioreactor. Biotechnol Prog 16:378-384. https://doi.org/10.1021/bp0000149

8. Cankorur-Cetinkaya A, Dereli E, Eraslan S, et al (2012) A novel strategy for selection and validation of reference genes in dynamic multidimensional experimental design in yeast. PLoS One 7:e38351. https://doi.org/10.1371/journal.pone.0038351

9. Cho RJ, Campbell MJ, Winzeler EA, et al (1998) A genome-wide transcriptional analysis of the mitotic cell cycle. Mol Cell 2:65-73. https://doi.org/10.1016/S1097-2765(00)80114-8

10. Crosman JT, Pinchuk RJ, Cooper DG (2002) Enhanced biosurfactant production by Corynebacterium alkanolyticum ATCC 21511 using self-cycling fermentation. J Am Oil Chem Soc 79:467-472. https://doi.org/10.1007/s11746-002-0507-5

11. Davison SA, den Haan R, van Zyl WH (2016) Heterologous expression of cellulase genes in natural Saccharomyces cerevisiae strains. Appl Microbiol Biotechnol 100:8241-8254. https://doi.org/10.1007/s00253-016-7735-x

12. Dawson PSS (1965) Continuous phased growth, with a modified chemostat. Can J Microbiol 11:893-903. https://doi.org/10.1139/m65-119

13. Dawson PSS (1972) Continuously synchronised growth. J Appl Chem Biotechnol 22:79-103. https://doi.org/10.1002/jctb.2720220112

14. Feldmann H (2012) Yeast: Molecular and Cell Biology. Wiley-Blackwell

15. Fitch I, Dahmann C, Surana U, et al (1992) Characterization of four B-type cyclin genes of the budding yeast Saccharomyces cerevisiae. Mol Biol Cell 3:805-818. https://doi.org/10.1091/mbc.3.7.805

16. Fritsch M, Starruß J, Loesche A, et al (2005) Cell cycle synchronization of Cupriavidus necator by continuous phasing measured via flow cytometry. Biotechnol Bioeng 92:635-642. https://doi.org/10.1002/bit.20647

17. Futcher B (1996) Cyclins and the wiring of the yeast cell cycle. Yeast 12:1635-1646. https://doi.org/10.1002/(SICI)1097-0061(199612)12:16<1635::AID-YEA83>3.0.C0;2-0

18. Hughes SM, Cooper DG (1996) Biodegradation of phenol using the self-cycling fermentation (SCF) process. Biotechnol Bioeng 51:112-119. https://doi.org/10.1002/(SICI)1097- 
0290(19960705)51:1<112::AID-BIT13>3.0.C0;2-S

19. Levy S, Barkai N (2009) Coordination of gene expression with growth rate: A feedback or a feedforward strategy? FEBS Lett 583:3974-3978. https://doi.org/10.1016/j.febslet.2009.10.071

20. Livak KJ, Schmittgen TD (2001) Analysis of relative gene expression data using real-time quantitative PCR and the 2- $\triangle \triangle C T$ method. Methods 25:402-408.

https://doi.org/10.1006/meth.2001.1262

21. Marchessault $P$, Sheppard JD (1997) Application of self-cycling fermentation technique to the production of poly- $\beta$-hydroxybutyrate. Biotechnol Bioeng 55:815-820.

https://doi.org/10.1002/(SICI)1097-0290(19970905)55:5<815::AID-BIT12>3.0.C0;2-A

22. McCaffrey WC, Cooper DG (1995) Sophorolipids production by Candida bombicola using self-cycling fermentation. J Ferment Bioeng 79:146-151. https://doi.org/10.1016/0922-338X(95)94082-3

23. Miller GL (1959) Use of dinitrosalicylic acid reagent for determination of reducing sugar. Anal Chem 31:426-428. https://doi.org/10.1021/ac60147a030

24. Mookerjee S (2016) Directing Precursor Flux to Optimize cis,cis-Muconic Acid Production in Saccharomyces cerevisiae. Concordia University

25. Müller J, Dawson PS (1968) The operational flexibility of the phased culture technique, as observed by changes in the cell cycle of Candida utilis. Can J Microbiol 14:1115-1126. https://doi.org/10.1139/m68-187

26. Mustea I, Muresian T (1967) Crabtree effect in some bacterial cultures. Cancer 20:1499-1501. https://doi.org/10.1002/1097-0142(196709)20:9<1499::AID-CNCR2820200917>3.0.C0;2-Q

27. Sarkis BE, Cooper DG (1994) Biodegradation of aromatic compounds in a self-cycling fermenter (SCF). Can J Chem Eng 72:874-880. https://doi.org/10.1002/cjce.5450720514

28. Sauvageau D, Cooper DG (2010) Two-stage, self-cycling process for the production of bacteriophages. Microb Cell Fact 9:1-10. https://doi.org/10.1186/1475-2859-9-81

29. Sauvageau D, Storms Z, Cooper DG (2010) Synchronized populations of Escherichia coli using simplified self-cycling fermentation. J Biotechnol 149:67-73.

https://doi.org/10.1016/J.JBIOTEC.2010.06.018

30. Sheppard JD (1993) Improved volume control for self-cycling fermentations. Can J Chem Eng 71:426-430. https://doi.org/10.1002/cjce.5450710312

31. Sheppard JD, Cooper DG (1991) The response of Bacillus subtilis ATCC 21332 to manganese during continuous-phased growth. Appl Microbiol Biotechnol 35:72-76. https://doi.org/10.1007/BF00180639

32. Sheppard JD, Cooper DG (1990) Development of computerized feedback control for the continuous phasing of Bacillus subtilis. Biotechnol Bioeng 36:539-545. https://doi.org/10.1002/bit.260360514

33. Sheppard JD, Dawson PSS (1999) Cell synchrony and periodic behaviour in yeast populations. Can J Chem Eng 77:893-902. https://doi.org/10.1002/cjce.5450770515 
34. Storms ZJ, Brown T, Cooper DG, et al (2014) Impact of the cell life-cycle on bacteriophage T4 infection. FEMS Microbiol Lett 353:63-68. https://doi.org/10.1111/1574-6968.12402

35. Storms ZJ, Brown T, Sauvageau D, Cooper DG (2012) Self-cycling operation increases productivity of recombinant protein in Escherichia coli. Biotechnol Bioeng 109:2262-2270. https://doi.org/10.1002/bit.24492

36. Tan Y, Agustin RVC, Stein LY, Sauvageau D (2022) Transcriptomics analysis of synchrony and productivity in self-cycling fermentation of engineered yeast producing shikimic acid. Biotech Reports, in press.

37. Teste MA, Duquenne M, François JM, Parrou JL (2009) Validation of reference genes for quantitative expression analysis by real-time RT-PCR in Saccharomyces cerevisiae. BMC Mol Biol 10:1-15. https://doi.org/10.1186/1471-2199-10-99

38. Untergasser A, Cutcutache I, Koressaar T, et al (2012) Primer3-new capabilities and interfaces. Nucleic Acids Res 40:1-12. https://doi.org/10.1093/nar/gks596

39. van Walsum GP, Cooper DG (1993) Self-cycling fermentation in a stirred tank reactor. Biotechnol Bioeng 42:1175-1180. https://doi.org/10.1002/bit.260421007

40. Wang J, Chae M, Beyene D, et al (2021) Co-production of ethanol and cellulose nanocrystals through self-cycling fermentation of wood pulp hydrolysate. Bioresour Technol 330:124969. https://doi.org/https://doi.org/10.1016/j.biortech.2021.124969

41. Wang J, Chae M, Bressler DC, Sauvageau D (2020) Improved bioethanol productivity through gas flow rate-driven self-cycling fermentation. Biotechnol Biofuels 13:1-14. https://doi.org/10.1186/s13068-020-1658-6

42. Wang J, Chae M, Sauvageau D, Bressler DC (2017) Improving ethanol productivity through selfcycling fermentation of yeast: a proof of concept. Biotechnol Biofuels 10:193. https://doi.org/10.1186/s13068-017-0879-9

43. Wentworth SD, Cooper DG (1996) Self-cycling fermentation of a citric acid producing strain of Candida lipolytica. J Ferment Bioeng 81:400-405. https://doi.org/10.1016/0922-338X(96)85140-3

44. Zenaitis MG, Cooper DG (1994) Antibiotic production by Streptomyces aureofaciens using selfcycling fermentation. Biotechnol Bioeng 44:1331-1336. https://doi.org/10.1002/bit.260441109

\section{Figures}



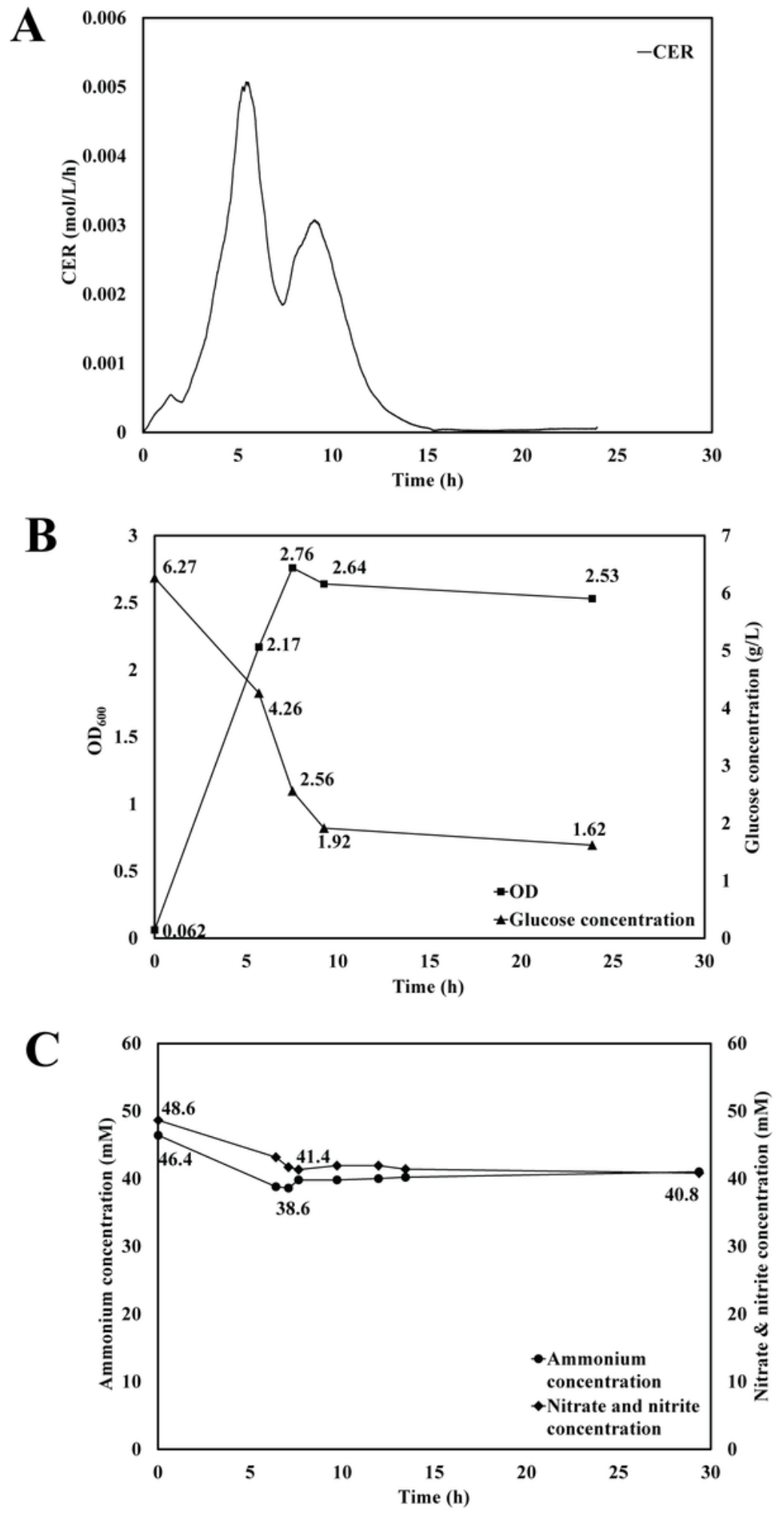

\section{Figure 1}

Growth of E. coli MG1655 in extended batch operation. A Carbon dioxide evolution rate (CER). B OD600 and glucose concentration. C Concentrations of ammonium, and combined nitrate and nitrite. 

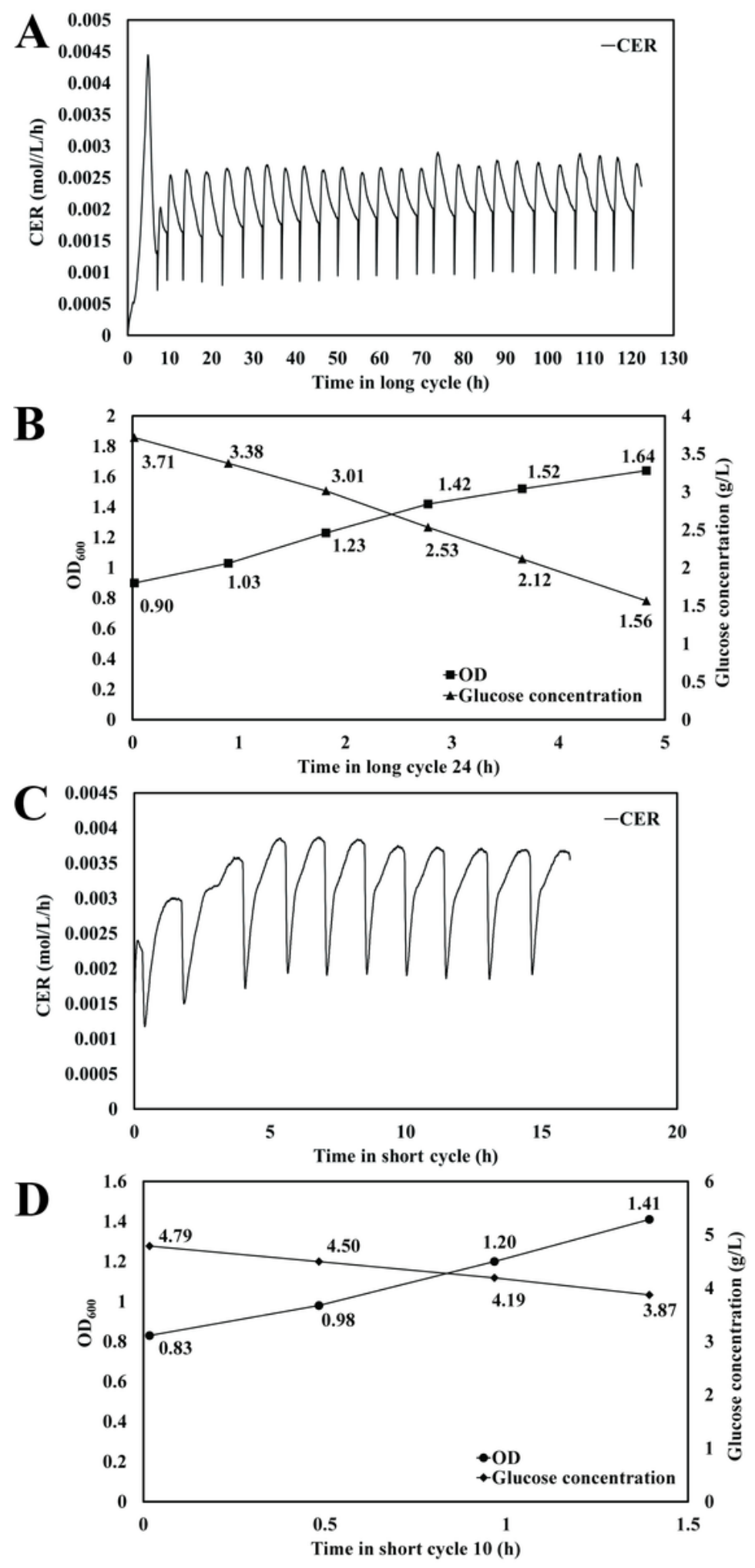

\section{Figure 2}

E. coli grown in SCF long cycle and short cycle schemes. A CER during long cycle operation. B Intracycle OD600 and glucose concentration during long cycle 24. C CER during short cycle operation. D Intracycle OD600 and glucose concentration during short cycle 10. 
A

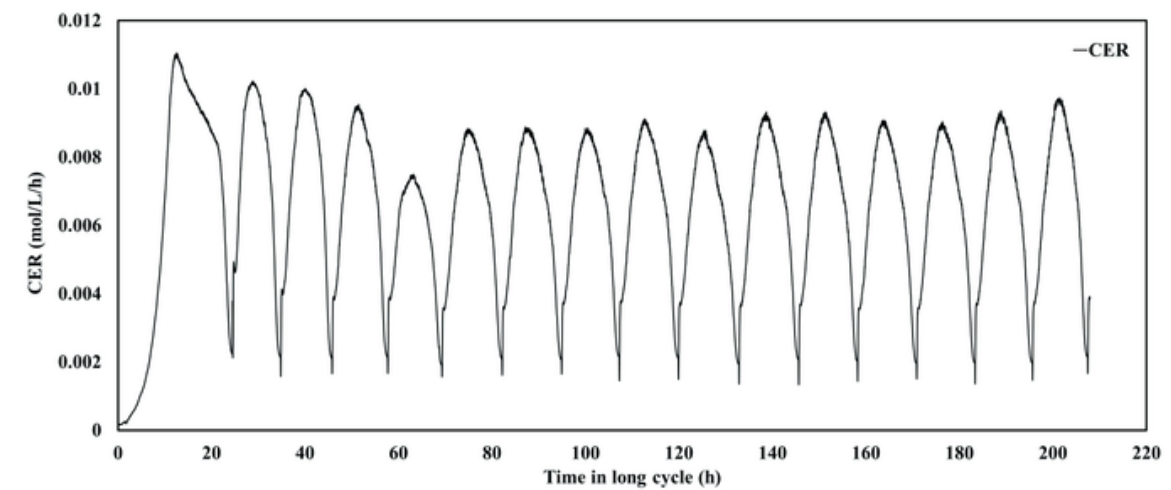

B

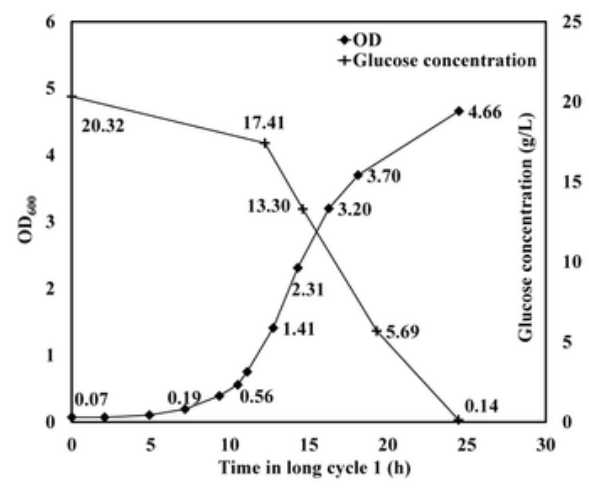



D

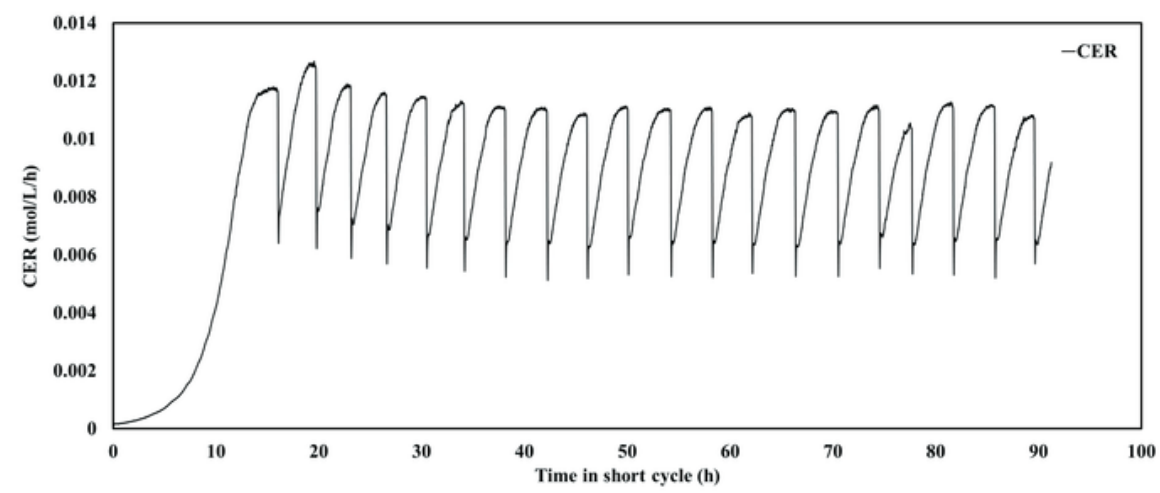

$\mathbf{E}$
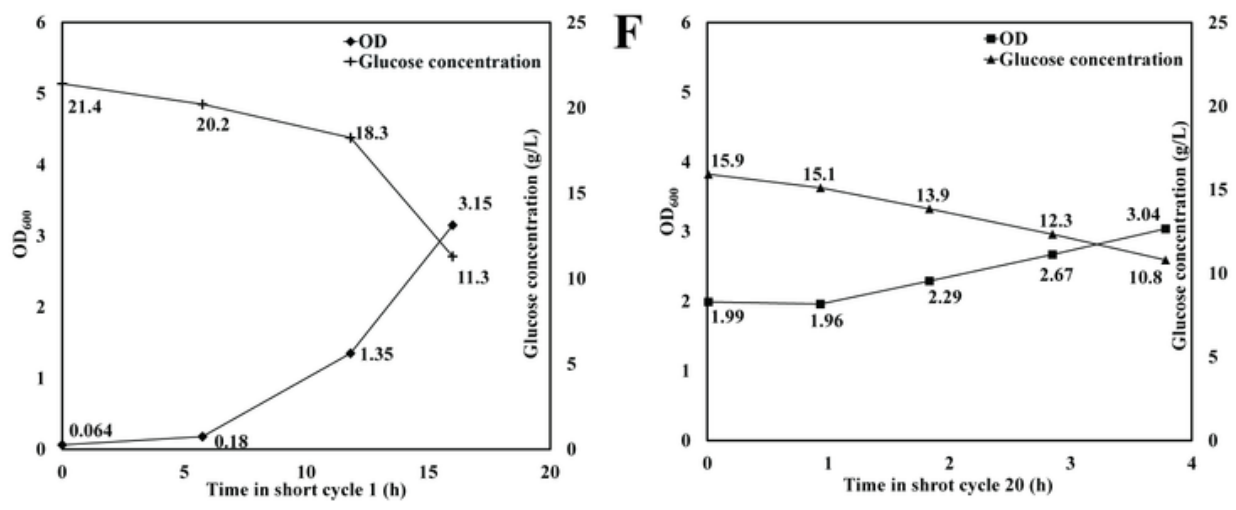

Figure 3

S. cerevisiae grown in SCF long and short cycle strategies. A CER during long cycle operation. B OD600 and glucose concentration during long cycle 1 (BR). C OD600 and glucose concentration during long cycle 10. D CER during short cycle operation. E OD600 and glucose concentration during short cycle 1 (BR). F OD600 and glucose concentration during short cycle 20. 

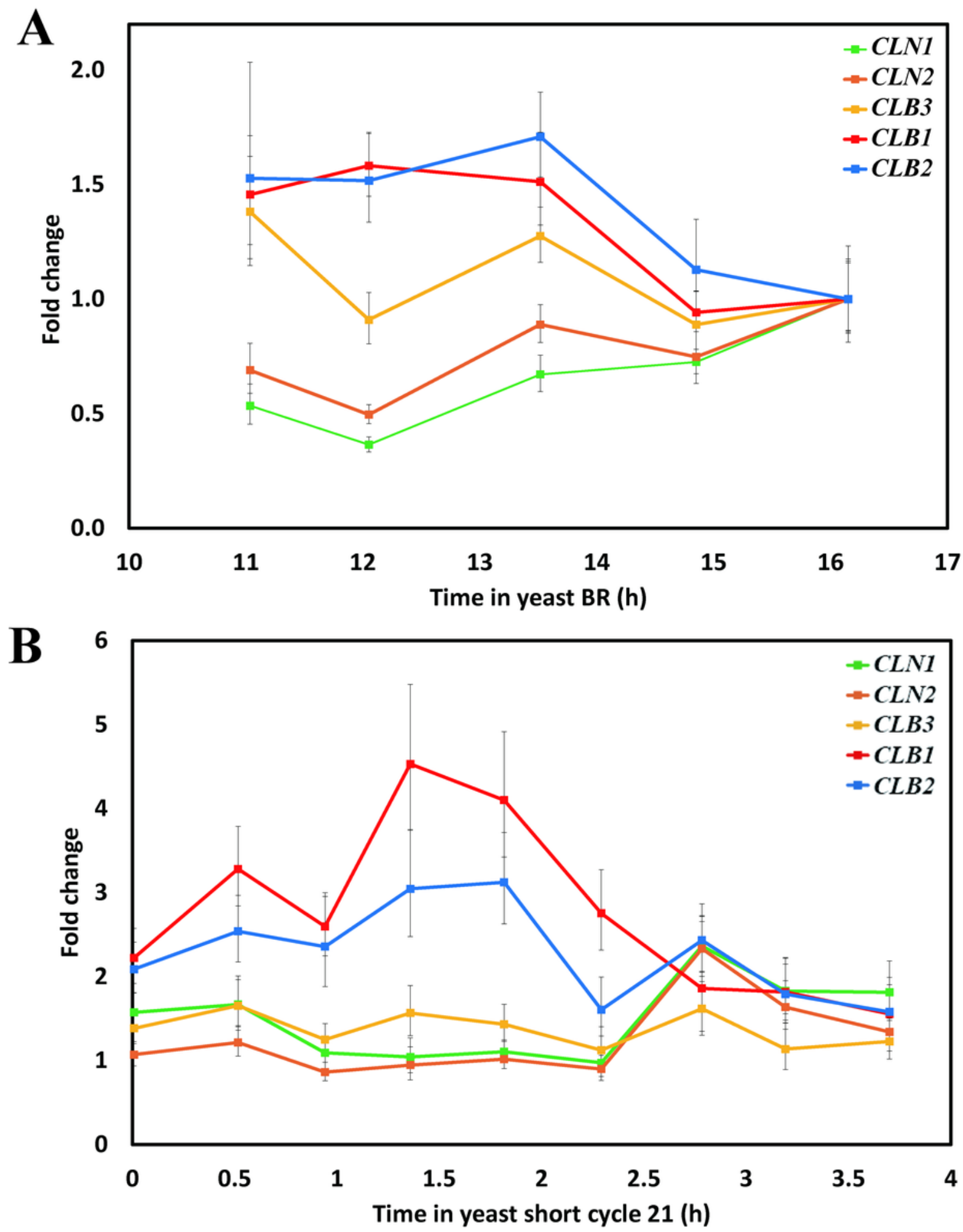

Figure 4

Relative expression levels of selected S. cerevisiae cyclin genes. A fold changes of CLN1, CLN2, CLB3, CLB1, and CLB2 during BR late-log phase. B fold changes of the same cycling genes during SCF short cycle 21. ACT1 and ALG9 were used as reference genes, and a sample collected at $16.2 \mathrm{~h}$ during BR was used as the reference sample. Error bars show one standard deviations $(n=3)$. (Colored Figure in print) 
A

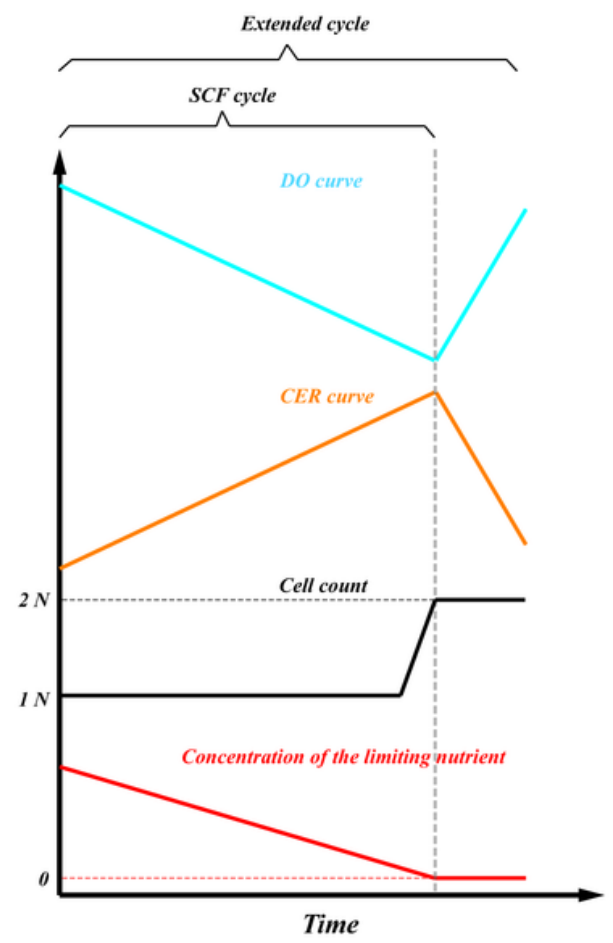

Trend A
B

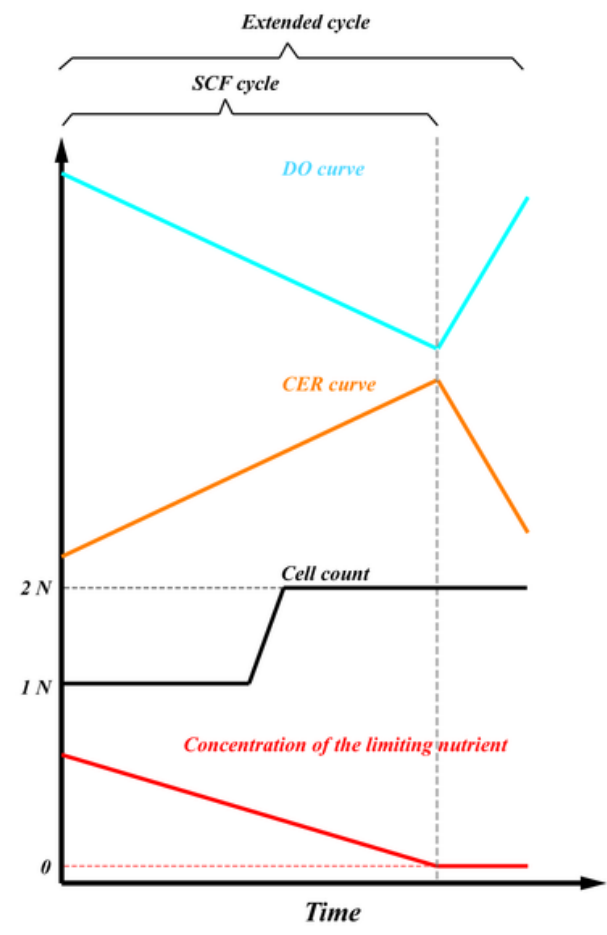

Trend B
C
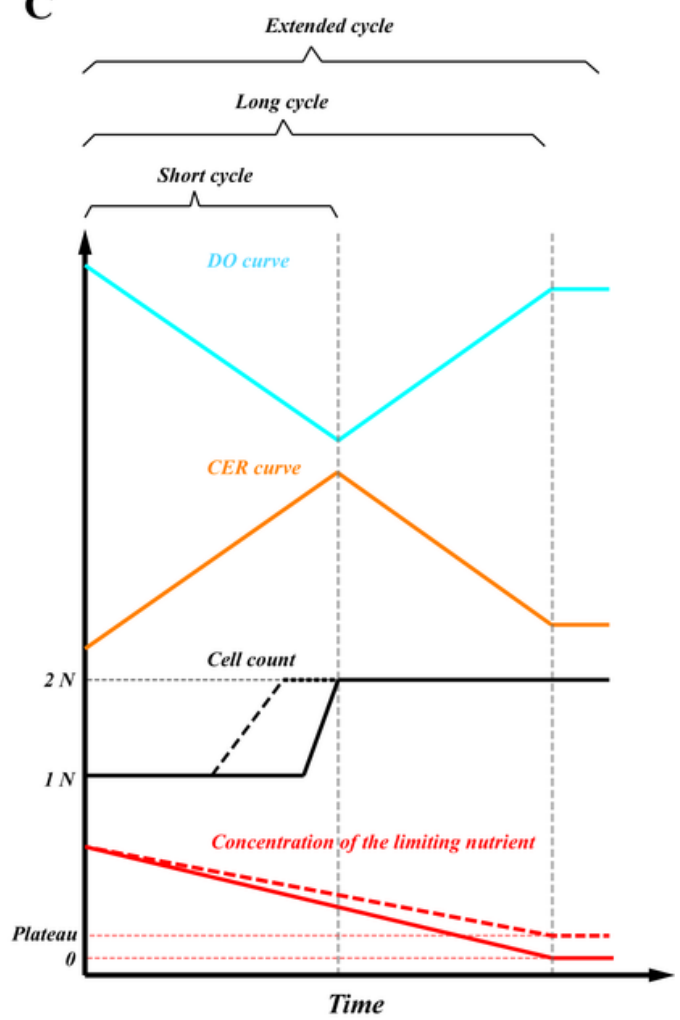

Trend C

Figure 5

Schematic of the conceptual trends in characteristic events during SCF. DO curve is shown in blue, CER curve in orange, cell count in black, and concentration of the limiting nutrient in red. Straight lines are used to describe changes but do not necessarily represent linear changes. A In Trend A, DO minimum or CER maximum, the end of synchronized cell replication, and the depletion of the limiting nutrient co-occur at the end of an SCF cycle. An extended cycle allows a delay in cycling. B In Trend B, DO minimum or CER maximum, and the depletion of the limiting nutrient co-occur at the end of an SCF cycle, but synchronized cell replication ends in the middle of the cycle. An extended cycle allows a delay in cycling. C In Trend C, the flattening of DO increase or CER decrease, and the depletion of the limiting nutrient (or a plateau, the red dashed line) co-occur at the end of an SCF long cycle, but synchronized cell replication ends in the middle of the long cycle, corresponding to DO minimum or CER maximum. An SCF short cycle ends at DO minimum or CER maximum, but partially synchronized cell replication likely starts and ends in the middle of the short cycle (the black dashed line). The limiting nutrient is not depleted by the end of the short cycle. An extended cycle allows a delay in cycling beyond the end of a long cycle. (Colored Figure in print)

\section{Supplementary Files}

This is a list of supplementary files associated with this preprint. Click to download.

- ProcessAbstract.jpg 
- SupportinglnformationBioresBiopro.docx 